\title{
Fingerprint Forensic Analysis Function in the Inquiry Process Uncovering Murder Cases
}

\author{
Megawati Barthos \\ Borobudur University \\ \{megawati_barthos@borobudur.ac.id\}
}

\begin{abstract}
Based on Criminal Code Procedures, related to making light of the case, the investigators are bound to Article 183 to Article 189 Criminal Code Procedures. The method of approach used is normative juridical empirical, which is legal research conducted by examining library materials or secondary data. Hasil pembahasan ini akan menerangkan tentang Function and Role of Fingerprint Forensics in the Inquiry Process Uncovering Murder Cases, and Factors Inhibiting the Inquiry Process if Uncovering Murder Using Fingerprints.
\end{abstract}

Keywords: Fingerprint; Forensic; murder cases

\section{Introduction}

This Word document can be used as a template for journal. This Word document can be used as a template for journal. This Word document can be used as a template for journal. This Word document can be used as a template for journal. This Word document can be used as a template for journal.

Based on Criminal Code Procedures, related to making light of the case, the investigators are bound to Article 183 to Article 189 Criminal Code Procedures. In principle, proof in criminal procedural law aims to seek material truth, so the evidence required can be in the form of witness statements, expert statements, letters, instructions, also the suspect/defendant statements. In accordance with Chapter XVI Part Four Article 183 to 189 Criminal Code Procedures explaining about the issues of proof or evidence, it means that the Law Enforcements such as the police, attorney, and judges will easily prove the material truth if the witness could exhibit evidence of the suspect/defendant's wrongdoing in the crime, but on the contrary, it will be difficult if the witness could not found or exhibit any evidence of the suspect's wrongdoing. The things found at the scene are collected for investigation and examination are possible to be used as evidence.

In solving a criminal case, there needs to be proof either with evidence or physical evidence to convince the judge in considering a sentence. In order to seek and find the complete material truth about a criminal act that has occurred, it is necessary to conduct an inquiry and investigation. The inquiry itself is a process of studying and knowing what happened in the past and in relation to the purpose of the inquiry. In carrying out the duties assigned to the inquirers and investigators, inquirers generally utilize sources of information to make clear of the case. 
The sources of information that the inquirers and investigators use to find out what happened are physical evidence, documents and records, and people (victims, eyewitnesses, suspected perpetrators of crimes, or anything else related to the victim, suspect, and circumstances at the crime scene).

One of the most common criminal incidents is murder. A murder is caused by many things, it can occur because of the relationship between a vulnerable person, a jealousy, unexpected theft that leads to the end of one's life, premeditated murder, and others. Sometimes, a murder takes a long time to solve, even there are also cases that are not solved at all. Nowadays in the inquiry and investigation of a criminal act is a necessity to apply proof and examination of physical evidence scientifically. Therefore, to solve a murder case, inquirers need forensic assistance.

Forensic can be done in many ways. One of them is the help of forensic laboratory examination. In this case, a forensic laboratory examination is a lab examination that applies science to find the material truth. Forensic laboratory examination Forensic laboratory examinations include forensic identification, genetics, corpses, chemical analysis, physical analysis, and everything related to the human bodies. For example, in a murder case where no other evidence is found other than fingerprints left behind, the investigation to uncover the cause of death by prioritizing fingerprint examination serves to compare the fingerprints left at the crime scene with the alleged suspect. The results of research and examination of forensic laboratories in the form of an official report of evidence examination is a valid evidence at the trial.

In addition to the help of forensic laboratories, there is also an identification unit, where the task is almost the same as a forensic laboratory. The Identification Unit called INAFIS (Indonesia Automatic Fingerprint Identification System) refers more specifically to the matter of fingerprint identification, as well as other matters in examining physical evidence at the crime scene carefully and observantly. Many of murder cases were eventually revealed due to fingerprint assistance. Examples include the murder of a Retired Navy Officer Hunaedi and the murder of Vera Oktaria:

In the first case, South Jakarta Metro Police Inquirers found fingerprints of suspected perpetrators of the murder of Retired Navy Officer Hunaedi. South Jakarta Metro Police Chief Kombes Pol Indra Jafar said, investigators obtained fingerprints of the alleged perpetrator at the crime scene at Hunaedi's residence, Cilandak, South Jakarta. The Identification Team and Forensic Laboratory are currently examining the fingerprints. Inquirers obtained fingerprints of alleged perpetrators placed in several places, namely at the front door, on the doorknob, then on Hunaedi's body.

The second case, the murder of Vera Oktaria. The sadistic case of Vera Oktaria's murder through mutilation in South Sumatra continues to be revealed. The South Sumatra Regional Police continued to attempt to dismantle Vera Oktaria's murder by mutilation in her lodging. A room where Vera Oktaria lived was found to have traces of a suspected perpetrator of Vera Oktaria's murder. As a result of the investigation, officers obtained fingerprints on the walls of Vera Oktaria's room which allegedly belong to the perpetrator. "The fingerprints were taken to Forensic Laboratory Center and will be examined first," said Habid Public Relations Police South Sumatra, Kombes Pol Supriadi.

Thus, in terms of proof of a murder case or persecution there needs to be evidence that strengthens to be a clue who is the perpetrator and what is the cause of death. All of that is needed by the agencies in charge of proving, namely forensic laboratories, as well as a unit needed at the site of the case, such as INAFIS (Indonesia Automatic Fingerprint Identification System). The existence of such a team for the purposes of criminal investigation is 
indispensable. The INAFIS team is part of the police force, which plays an important role in carrying out the task of assisting in evidentiary and uncovering cases. The investigation of the crime is not only based on eye witness, but also on physical evidence found at the scene. Therefore, the role of fingerprint forensics is very helpful for inquiry and investigation.

\section{Method}

The method of approach used is normative juridical empirical, which is legal research conducted by examining library materials or secondary data as the basic material to be researched by conducting a search of regulations and literature related to the problem studied, and empirical, which means based on data that occurs in the field. The data used in this research is secondary data that includes official documents, books, research results and results obtained through literature studies and field studies. After all the data is collected then classified according to the instructions. Then analyzed systematically by approaching legislation, methods, norms, and teachings related to the problem to be examined, until a conclusion can be drawn.

The data presented is descriptive, meaning that research will be conducted on case studies in accordance with the provisions of the applicable law and in the application of the law in accordance with the facts of the incident. Therefore, researchers will approach the applicable legislation which in practice is related to the problems to be studied.

\section{Discussion}

\subsection{Function and Role of Fingerprint Forensics in the Inquiry Process Uncovering Murder Cases}

A murder act is an act of intentionality committed by the perpetrator in terms of losing the lives of others. In uncovering a murder act, many need to be carefully considered. Starting from the victim, the crime scene, and why the suspect did it. As in the inquiry system used by the Police of the Republic of Indonesia, the system to try and disclose the points of issue as:
a. Who the victims, perpetrators, witnesses are, etc.
b. What happened, what crime?
c. Where has happened.
d. With what tools are used.
e. Why, what is the motive, the reason.
f. How to do it.
g. Where the incident is done (the time of the incident).

Murder crimes that occur in Indonesia in general still often leave the fingerprints of the perpetrator, except in crimes that have actually been planned by the perpetrator. Therefore, the thoroughness of inquirers in finding the fingerprints of the perpetrators left at the crime scene is very necessary. Because human fingerprints are not the same and are permanent in nature, the use of fingerprints in revealing one's identity is fairly accurate and convincing.

The function of the use of fingerprints in uncovering a criminal act is classified as one of the necessary processes in the inquiry. This fingerprint can be used in identifying the perpetrator of a crime, where in a murder act, a criminal or suspect may leave a clue at the crime scene, such as latent fingerprints that are on the physical evidence or elsewhere. These 
fingerprints can also be used to identify victims who are not identified in a murder crime. Therefore, the use of fingerprints in uncovering criminal acts is very important.

In accordance with Article 14 clause (1) letter (h) of Law No. 4 of 2002 concerning the State Police of the Republic of Indonesia states that, the State Police of the Republic of Indonesia carries out duties where one of them is:

"Conducting police identification, police medicine, forensic laboratories and police psychology for the benefit of police duties."

The implementation of police identification or commonly called identification unit or INAFIS (Indonesia Automatic Fingerprint Identification System) is intended for the purposes of criminal investigation (law enforcement) and public services for the community. INAFIS which is an institution of Police Headquarters plays an important role in fostering and carrying out identification functions in order to support the inquiry or law enforcement carried out by the police and related interests in accordance with the policy of the Head of Indonesian Criminal Investigation Agency. INAFIS provides operational technical support of the National Police, especially support in the inquiry process, fingerprint information services, photography and facial identification, for internal and external purposes of the National Police.

With INAFIS, the inquiry process in carrying out matters related to fingerprints becomes easier. The implementation of INAFIS's functions in helping to uncover murder crimes in general includes:

a. Carrying out crime scene activities;

b. Photographing crime scene reconstruction;

c. Carrying out the search and collection of physical evidence;

d. Examine and develop latent fingerprints on evidence;

e. Photographing crime scenes, latent fingerprints, evidence, victims, witnesses and perpetrators;

f. Sketch a crime scene; and

g. Sketch a face and reconstruct the facial expression.

INAFIS (Indonesia Automatic Fingerprint Identification System), especially in the field of criminal dactyloscopy in carrying out its duties in fostering and carrying out the function of identification of criminal cases need to analyze the request from inquirers in the form of a application cover letter.

The letter containing an application to INAFIS and other police agencies to examine crime scenes and evidence is contained in the Chief of Police Regulation No. 10 of 2009 concerning Procedures and Requirements for Technical Examination of Criminalistics Crime Scenes and Laboratory of Criminalistics Evidence to the Forensic Laboratory of the State Police of the Republic of Indonesia. Based on Chief of Police Regulation No. 10 of 2009 Article 5 clause (1), criminalistics technical examination of crime scenes can be fulfilled upon request from: Police inquirers; Civil Servant Inquirers; Prosecutors; Court; Indonesian National Army Military Police; and Other agencies in accordance with the scope of their authorities.

After the request letter is received and analyzed, the criminalistics technical examination of the crime scene is carried out by the INAFIS team and inquirers in an integrated and proportionate manner. In order to smooth the technical examination of criminalistics crime scenes, inquirers must master the problems related to the murder case.

The implementation of the inquiry process on murder cases using fingerprints makes it very easy for inquirers to uncover a criminal case. Fingerprint function in murder case can be used to identify the perpetrator by carrying out crime scene and conducting examination of evidence. The process is carried out in accordance with SOP procedures (Standard Operational Inquiry). The inquiry steps begin with visiting the crime scene, making public observations to 
find out what happened, conducting searches to find evidence, as well as photograph and sketching.

To be able to facilitate the process of fingerprint identification, often at the time of the crime scene when conducted crime scene and looking for evidence contained and suspected fingerprints of the perpetrator, used a variety of dactyloscopy tools, such as: Ordinary powder; Magnetic powder; Fingerprint ink; Fingerprint brush; AK-23 card; Gloves and masks; Polylight photography; and Evidence bag.

In terms of fingerprint identification if fingerprints have been obtained found at the crime scene, it will be developed first to make its clearer fingerprints and compared to the person suspected as a suspect. For evidence found at the crime scene that is suspected to have latent fingerprints can be done directly at the crime scene or taken to the laboratory, depending on the condition of the evidence. Therefore, in order to maintain the authenticity of a crime scene, the police provide a boundary line (police line) with the aim of keeping the authenticity of the crime scene maintained.

In conducting fingerprint comparisons, the INAFIS team already has comparisons in the police database. The database in question is fingerprint collection for data collection and filing and recording in order to reproduce or enrich the fingerprint database for the purposes of the general public in the framework of the process of confirming the correctness of identity (eKTP/e-ID) and criminal records of a person.

To check the fingerprint between one person and another, or commonly known as fingerprint comparison has a basis or technical instructions implementation, namely Technical Guide No. Pol: Juknis/05/V/1981 dated May 30, 1981 on Fingerprint Comparison Examination. This was later revised by Technical Guide No. Pol: Juknis/05-A/V/1998 dated March 9, 2000. The steps that should be considered before doing fingerprint comparison are as follows:

a. Before latent fingerprints are compared to suspect fingerprints or fingerprints stored in files on behalf of a particular person, firstly, latent fingerprints compared to the fingerprints of people who have legitimately held something at the crime scene (elimination prints).

b. Determine the origin of the finger: (1) In general latent fingerprints are side by side with each other (located side by side/combination). To make the examination easier, it is necessary to determine in advance which finger/hand the latent finger comes from. (2) Some of the following can be used as a handle in determining the origin of the finger/hand of a latent fingerprint.

1. Generally people always hold objects with their right hand.

2. The index finger, middle finger, ring finger, and pinkie are generally accompanied. As for generally, the thumb itself.

3. The size of the large and long fingers and their link with each other.

c. Determine the equation/identity of two fingerprints. To determine whether two fingerprints are identical.

d. How/technique of checking fingerprint comparison:

1. Latent fingerprints or suspected fingerprints are placed side by side with known fingerprints on the fingerprint comparator. Then, using the equipment immediately began to compare the two fingerprints. Keep in mind, comparison checks begin with latent fingerprints to known fingerprints, not the other way around. 
2. Determine whether the two fingerprints have the same painting principal shape. If the basic shape of the painting is not intact, note whether the flow of papillary lines between the two fingerprints is the same.

3. If the shape of the two points of painting both fingerprints are different or not the same, it is certain that the two fingerprints are not identical. Therefore, further examination does not need to continue.

4. If the basic shape of the painting or the flow of the papillary lines of both fingerprints are the same, a detailed examination should be carried out further.

In addition to identifying the perpetrator, as mentioned earlier the use of fingerprints can also be used to identify victims who are not known identity. The murder of the unidentified victim continues in a forensic identification examination. Forensic identification was also carried out on the dead or unidentified bodies, bodies in a state of disrepair due to rot, burning, mutilated corpses, and so on. The forensic identification was carried out to find out who the victim was and continued to find out what the cause of death was.

The bodies of unidentified victims of crime will find it difficult to find the perpetrator so there can be no legal process. In the examination of legal cases, errors in identification can be fatal, in criminal, civil and administrative cases. In the practice of determining a person's identity, from existing methods of identification, not all of them are used. Primary identification method in the form of fingerprint and tooth examination that can stand alone without the help of other identification methods, because there are almost no identical fingerprints and teeth between two different people, so fingerprint and tooth examination has a high validity.

Forensic identification using fingerprints is not done directly by the doctor, but the doctor is still obliged to take or print fingerprints (especially the fingerprints of the deceased and the state of his decomposed corpse), fingerprint development techniques on wrinkled fingers, as well as remove the skin of the fingertips that have peeled off and attach them to the appropriate fingers, only then do the fingerprinting. Furthermore, fingerprint checks are carried out by the police or identification unit (INAFIS).

Fingerprint identification of victims of murder crimes is generally a means to know, to record and to process victims to proceed to the next legal process. In the event that the victim of a murder crime is not known their identity then the identification process is carried out in order to identify the identity of the victim by conducting an autopsy by a forensic doctor on the victim in order to proceed to the next legal process.

Article 133 clause (1) of the Criminal Procedural Code states that: "In the event that an inquirer for the interests of the judiciary handles a victim either injured, poisoned or dead suspected of an event that is a criminal act, they are authorized to submit a request for expert information to a judicial medical expert or doctor and or other experts."

Looking at the function of fingerprints in uncovering murder crimes is very important in the role of identifying perpetrators and victims, investigators and INAFIS must carefully and observantly do their job. Because, the legal consequences when there is an error in persona of the accused against a case in the judicial process in accordance with Article 143 paragraph (3) Criminal Procedural Code is null and void.

Therefore, the accuracy in identifying for the determination of one's identity plays an important role in legal and social issues. Forensic identification checks are primarily intended to determine a person's identity, whether alive or dead.

As for Suci, PUSINAFIS staff in the field of criminal dactyloscopy provides examples as in the case of murder there are wounds or bruises on the physical or body of the victim, forensic medicine conducts an examination of the victim's body by conducting an autopsy to 
find out what the cause of death, what injuries are on the victim's body (wounds are located where, size, shape). From the wound, forensic doctors were able to determine what caused the wound. If the results of the autopsy by the doctor are numbered that the victim's death was caused by a stabbing with a knife against the victim's body, and it is true that a knife was found at the crime scene with fingerprints of the suspected perpetrator, then inquirers need to conduct further investigation to make light of the incident. The link between the forensic doctor's autopsy results and the evidence found at the crime scene gives inquirers more confidence to establish the alleged perpetrator whose fingerprints were on the physical evidence with the results of the autopsy further explaining that it is true that the evidence was used in the incident.

The results of the autopsy performed by the forensic doctor are contained in or referred to as Visum et Repertum, where according to Abdul Mun'im Idries is a written report from the doctor who has been sworn about what is seen and found on the evidence he examined and contains also the conclusions of the examination for the benefit of the judiciary. As the author has explained before, fingerprint science (dactyloscopy) used in the process of inquiring murder acts can make light of the case because from the examination of the fingerprint results produce Investigation and Interrogation Report that is a valid evidence in the case at trial.

INAFIS team that also has expertise that because of their knowledge, skills, experience, training, or education on fingerprint science can be used as an expert in the proceedings and can be used as a consideration of the judge. Therefore, the use of fingerprints in the inquiry process can be used as evidence of expert information and valid reports. Regarding valid evidence, Article 184 clause (1) of Criminal Procedural Code states that: "Valid evidence is: Witness testimony; Expert testimony; Reports; Clues; Defendant testimony."

As for the expert testimony contained in Article 1 point 28 and Article 186 Criminal Procedural Code. Article 1 point 28 Criminal Procedural Code states that: "Expert testimony is information provided by a person who has special expertise on what is necessary to make light of a criminal case for the purposes of examination". Article 186 Criminal Procedural Code states that: "Expert testimony is what the expert stated at the trial."

With the evidence and physical evidence produced by fingerprint science (dactyloscopy), inquirers in the inquiry process can help uncover the occurrence of murder acts factually by conducting examinations based on the task of inquirers. This paved the way for the judge's conviction at the trial.

And also, based on the criminal procedural law that adheres to the negative evidentiary system where in the event, the criminalization is based on the legislation and the belief of the judge. Article 183 of the Criminal Procedural Code further states that: "The judge shall not sentence a person unless at least two valid pieces of evidence are found to have a conviction that a crime actually occurred and that the accused is guilty of doing so."

Therefore, fingerprint science (dactyloscopy) is very helpful for police inquiries to uncover murder acts that occur. That's because fingerprints are permanent (can't change) and have the highest level of accuracy among other methods is the most important thing to determine who the suspect is and identify the victim and make light of a criminal event that occurred.

\subsection{Factors Inhibiting the Inquiry Process if Uncovering Murder Using Fingerprints}

In the ongoing process of murder act inquiry using fingerprint as assistance (dactyloscopy), sometimes inquirers experienced obstacles in carrying it out. According to Ade Haryanto as a staff of PUSINAFIS (Indonesia Automatic Fingerprint Identification System Center), the use of fingerprints in uncovering cases of murder by INAFIS is estimated 
to reach $70 \%$ of all existing cases although not all cases are revealed due to obstacles. The obstacles that exist in uncovering a murder acts usually occur due to factors:

\section{a) Legal Factor}

Currently, the use of fingerprint science (dactyloscopy) is only stipulated in Article 7 clause (1) letter (f) Criminal Procedural Code and Article 15 clause (1) letter (h) of Law No. 2 of 2002 on the State Police of the Republic of Indonesia concerning the authority to take fingerprints by inquirers. As a result of this, inquirers often ignore the use of fingerprints in the inquiry process because the use of fingerprint science is only as the authority of the inquirers and is not a necessary thing in every inquiry process.

\section{b) Officers}

Officers have an important role in processing crime scenes to gather evidence in the inquiry process. Officers must have skills regarding fingerprints in the inquiry process, because if the officer does not master the knowledge of identification then there will be difficulty in finding evidence or even damaging the traces of the perpetrator who should be used as evidence.

\section{c) Public}

According to Suci as a staff of PUSINAFIS (Indonesia Automatic Identification System Center) in the field of criminal dactyloscopy, people who are at the crime scene become obstacles to uncover criminal cases. This is because of the enthusiasm or curiosity of the public towards the murder act and the lack of understanding of fingerprints will make it difficult for inquirers and INAFIS team in carrying out crime scenes and identifying physical evidence. The public may damage the fingerprints left at the crime scene, making it difficult for officers to do their job.

\section{d) Weather or Climate}

Weather or climate greatly affects a situation at the crime scene. Weather conditions, humidity, air temperature, temperature changes at crime scenes can damage the latent fingerprints left by the perpetrator. Weather or climate factors are natural inhibitors that can occur anywhere and anytime, this can result in the loss of latent fingerprints and blurring of latent fingerprints on a piece of evidence.

\section{e) Animals}

Obstacles can also come from animals. The obstacle in question is the presence of animals that can damage the crime scene by tearing or gnawing at the victim's lifeless body and an unknown identity so that the identification officer is difficult to identify the victim. Animals can also damage crime scenes by moving physical evidence or blurring the offender's tracks, making it difficult for inquirers to process the crime scene.

\section{f) Object Texture (Physical Evidence)}


Ade Haryanto as a staff of The Sub Division of Resources at PUSINAFIS also said that the texture of the evidence is an obstacle received by the identification officer. The texture of the evidence may affect the results of existing latent fingerprints. According to him, objects such as glass are very easy to find latent fingerprints, while media objects that have a rough texture such as tables or items made of woods are difficult to find latent fingerprints.

As the author explained about the inhibitory factors, Suci as PUSINAFIS staff also added some things about the difficulties faced by officers when identifying damaged latent fingerprints, namely: Imperfect latent fingerprints; Plural fingerprints, overlapping each other; A short period of fingerprints caused by the composition of latent fingerprints or the amount of sweat released by the perpetrator, material attached to the fingerprint, fingerprint position, and psychological state of the perpetrator.

\section{Conclusion}

Based on the results of the research that has been described in the previous chapters can be concluded as follows:

a. The function and role of fingerprints in uncovering a murder act is classified as one of the necessary processes in the inquiry. Fingerprints can be used in identifying the perpetrator of a crime, where in a murder act of, a criminal can leave a clue at the crime scene. Fingerprints can also be used to identify victims who are not identified in a murder crime through forensic identification. The role of fingerprint identification of victims and perpetrators of murder crimes is generally as a means to know, to record and to process victims to proceed to the next legal process. The result of fingerprint identification also plays a role in the inquiry process as a means of proof of expert testimony and valid reports based on Articles 184 and 186 Criminal Procedural Code.

b. Factors that inhibited the inquiry process uncovering murder acts using fingerprints, namely: (1) legal factors that only authorize investigators to use fingerprints, and do not require; (2) officers who have no knowledge of fingerprint identification; (3) lack of understanding of the public; (4) weather or climate affecting the state of the crime scene; (5) animals that may damage the crime scene; (6) the texture of the object (physical evidence) the fingerprints were founded. The obstacles of the officers when identifying damaged latent fingerprints can also hinder the inquiry process caused by imperfect latent fingerprints, overlapping fingerprints and due to a short period of fingerprints.

\section{References}

[1] Abdussalam, Forensic, Jakarta: Restu Agung, 2006,

[2] Abdul Mun'im Idries and Agung Legewo Tjiptomarnoto, Application Forensic Medicine in the Investigation Process, Jakarta: Sagung Seto, 2017

[3] Andi Hamzah, Principles of Criminal Law, Jakarta: PT Rineka Cipta, 2010

[4] Andi Hamzah, Indonesia Criminal Procedural Law, Jakarta: Sinar Grafika, 2019

[5] Harahap, M. Yahya, Discussion of Problems and Application of Criminal Procedural Code Investigation and Prosecution, Jakarta: Sinar Grafika, 2000

[6] Moeljatno, Principles of Criminal Law, Jakarta: PT Rineka Cipta, 2015

[7] Lamintang, Basics of Criminal Law in Indonesia, Jakarta: Sinar Grafika, 2014 
[8] Lamintang, Special Offenses on Crimes against Life, Body and Health and Crimes That Endanger Life, Body and Health, Bandung: Binacipta, 1985

[9] Y.A. Triana Ohoiwutun, Forensic Medical Sciences (Interactions and Legal Dependencies on Medical Sciences), Yogyakarta: Pohon Cahaya, 2008 